\title{
Dandy-Walker Syndrome - A Case Report
}

\author{
Halyna Bulak* and Dzvenyslava Kopanska \\ Danylo Halytsky Lviv National Medical University, Ukraine \\ *Corresponding author: Halyna Bulak, Associate Professor, Department of Paediatrics, Lviv City Children's Hospital, Ukraine
}

Submission: 悳 January 11, 2019; Published: 眥 February 15, 2019

\begin{abstract}
The number of congenital malformations, which are the main cause of early childhood mortality and disability has grown significantly over the past ten years. Congenital anomalies resulting in serious disorders often accompany pathology of the brain. The results of clinical observation of the patient with significant malformation of the central nervous system - Dandy-Walker syndrome, have been presented in this paper. Dandy-Walker syndrome occurs in one out of every 25,000 live births but is still not fully understood.
\end{abstract}

Keywords: Dandy-Walker syndrome; Hydrocephalus; Cerebellar dysfunction

Abbreviations: CNS: Central Nervous System; CPAP: Constant Positive Airway Pressure; CT: Computed Tomography; MRI: Magnetic Resonance Imaging

\section{Introduction}

In the structure of all congenital anomalies malformations of the central nervous system occupy the second place after the defects of the cardiovascular system. $80 \%$ of these disorders are manifested by hydrocephalus of various genesis. Among the large number of such anomalies, worst in its consequences, is the DandyWalker syndrome. Malformation or Dandy-Walker syndrome is a cerebral defect characterized by a triad of symptoms: agenesis or hypoplasia of the cerebellar vermis, cystic dilatation of the ventricles and enlargement of the posterior fossa.

\section{Case Presentation}

Here is a personal observation of a child with Dandy-Walker syndrome. At the age of two hours patient was hospitalized in the neonatal intensive care department of the Lviv City Children's Hospital with complaints about respiratory disorders and periodic seizures.

From the history of life, it is known that boy was first born in pathological delivery at 38 weeks period. From medical history mother have not taken any harmful substances during pregnancy. She also denied any other risk factors for the disease, including stress or other transmitted diseases during pregnancy. Apgar score at birth was $6 / 7$ points, weight $-2450 \mathrm{~g}$, length $-46 \mathrm{~cm}$. At the age of two hours, he entered the neonatal intensive care unit of the Lviv City Children's Hospital. The child was in heavy condition during admission. During the examination, he behaved languid with suppressed physiological reflexes. Auscultation of the lungs and heart showed no abnormalities. The abdomen during palpation was not painful. In the area of the nape, a hernial protrusion, which is covered with skin, is visualized. According to the neurosonography, there is a cyst of the posterior cranial fossa.

At the age of 3 days with a slight improvement, he was transferred to the department of pathology of the newborn into Lviv City Children's Hospital where was still treated for 4 days with a diagnosis: multiple defects in growth and development; congenital defect of the central nervous system: Dandy-Walker syndrome, occipital meningocele.

Due to the impairment of the state was transferred to the neonatal intensive care department. During the inspection reacted with motor distress. Needed oxygen therapy in CPAP mode. At the time of admission to the department, baby (7 days old) had a weight of $2450 \mathrm{~g}$, length $-46 \mathrm{~cm}$. The general condition of the child was moderate. The body temperature $-36,6^{\circ} \mathrm{C}$, heart rate -130 beats/ min., breathing frequency - 40 breaths/min. Objectively: pale skin, clean. Visible mucous: hyperemic, moist. Peripheral lymph nodes are not palpable. Respiratory system: shortness of breath through the nose, serous discharge. Auscultation of the lungs - no peculiarities. Cardio - vascular system: auscultation heart tones sonorous, rhythmic, auscultated systolic noise on top. Digestive system: the abdomen is not swollen, soft, available in all regions for palpation. The liver acts from the costal arch to $2.0 \mathrm{~cm}$, palpable. Stool formed without pathological impurities. Urination: free.

At the time of laboratory analysis, abnormal parameters of blood and urine tests were not found. Radiography of the chest: indirect signs of heart disease, lungs without pathological changes. Electrocardiogram: sinus tachycardia, heart rate - 130 beats/ min. Echocardiography: signs of an open oval window and open 
arterial duct. Neurosonography: signs of Dandy-Walker syndrome, side ventricles are dilated. Behind the third ventricle, the cystic formation is $14 * 9 * 7 \mathrm{~mm}$. The III ventricle is cystally extended. Occipital meningocele. Consultation of neurologist: suppressed physiological reflexes. Consultation of neurosurgeon: in the area of the nape visualized hernial bulging in size 2,0*1,5*1,0 cm, covered with skin. Consultation of urologist: polycystic kidney disease. After series of examinations and repeated neurosonography, a moderate progression of ventriculodulation was observed, resulting in a deterioration in the clinical picture of the child in the form of a progression of shortness of breath, the appearance of apnea and cramps.

On the basis of all clinical data and laboratory - instrumental examinations, the final diagnosis for this patient was as follows: multiple defects in growth and development; congenital defect of the central nervous system: Dandy-Walker syndrome, occipital meningocele. Congenital malformation of the genitourinary system: polycystic kidney disease. Congenital heart defect: open oval window and open arterial duct.

Parents of the child were offered an MRI examination for their child. But due to the difficult social status of this family, they abandoned this offer and under their responsibility took the child home from our clinic under the supervision of a family doctor. After receiving the symptomatic treatment of associated diseases, the boy was discharged home with recommendations relative to health issues in patients with the Dandy-Walker syndrome. Recommended: balanced nutrition, prevention of rachitis and clinical observation of pediatrician, neurologist, cardiologist and urologist and further operative treatment of meningocele and kidney defects.

\section{Discussion}

Dandy-Walker syndrome (atresia of the foramen of Magendie; hypoplasia of the cerebellar vermis) was described for the first time in 1914 by Dandy \& Blackfan [1] In 1942 T.K. Taggart and A.E. Walker talked about the clinical and morphological specifics of this anomaly, and already in 1954 C.E. Benda introduced the notion of Dandy-Walker malformation and described the triad of typical symptoms of this pathology: agenesis or hypoplasia of the cerebellar vermis, cystic dilatation of the ventricles and enlargement of the posterior fossa, which leads to hydrocephalus.

The etiology and pathogenesis of Dandy-Walker syndrome are not fully understood. This pathology is often associated with trisomy of 3q, 6p, 9p, 11th or 22th chromosome, and rarely with translocations of the 13th chromosome [2]. Syndrome may be associated with more than 70 different congenital syndromes, such as Walker-Warburg syndrome, Coffein-Siris and Meckel-Grouber syndrome.

Most authors believe that hydrocephalus in children with Dandy-Walker syndrome at the time of birth is absent, it develops during the first months of life. In $65 \%$ of cases, the syndrome is combined with other abnormalities of the brain: corpus callosum agenesis, encephalocele, heterotopy of the gray matter, also with polydactylia, syndactylia, congenital heart defects, polycystic kidney disease and palate clefts.

In most patients, symptoms are manifested from birth, but in $10-20 \%$ of patient's symptoms can develop at the beginning of adolescence [3]. In addition to the classic triad, other common symptoms are the delayed motor development, progressive increase of the skull, symptoms of elevated intracranial pressure, uncoordinated movements, seizures.

Dandy-Walker syndrome is diagnosed on the basis of objective examination, ultrasound, CT or MRI examination. Ultrasound picture of this syndrome is characterized by evidence of large cystic formation in the posterior cranial fossa; the cerebellum vermis is not determined; hemispheres of the cerebellum are sharply reduced in size and separated; the third and lateral ventricles are expanded to varying degrees. Neurosonographically, the vermis defect varies in size from a thin slit to a wide channel between the divided hemispheres. The degree of hydrocephalus occurs from a small dilation of the lateral ventricles to a pronounced occlusive watery [4].

Differential diagnostic of this malformation carried out with retrocerebral cysts. Pathognomonic sign of Dandy-Walker syndrome is agenesis or hypoplasia of the cerebellar vermis that is not marked in the hypoplasia of the cerebellum caused by other diseases. Extremely important is the prenatal diagnosis of DandyWalker syndrome, which is usually performed after 18 weeks of gestation.

The prognosis for life and health depends on the presence of concomitant developmental anomalies, chromosomal abnormalities, and the timeliness of the diagnosis. According to the literature, the rates of postnatal morbidity and mortality are higher in cases where the syndrome is diagnosed in the prenatal period, and not in the newborn.

Treatment depends on the severity of manifestations. The most common is surgical treatment, which include ventriculoperitoneal shunting and correction of concomitant multiple developmental abnormalities.

\section{Acknowledgement}

We would like to express gratitude to chief doctor of the Lviv City Children's Hospital - D. Kvit.

\section{Conflict of Interest}

The authors do not report any financial or personal connections with other persons or organizations, which might negatively affect the content of this publication and/or claim authorship rights to this publication.

\section{References}

1. Dandy WE, Blackfan KD (1914) An experimental clinical and pathological study. Am J Dis Child 8(6): 406-482.

2. Sikorski CW, Curry DJ (2005) Endoscopic single catheter treatment of dandy hydrocephalus: technical case report and review of treatment options. Pediatr Neurosurg 41(5): 264-268. 
3. Chitayat D, Moore L, Del Bigio MR, MacGregor D, Ben-Zeev B, et al. (1994) Dandy-Walker malformation macrocephaly, facial anomalies, developmental delay, and brain stem dysgenesis: prenatal diagnosis and postnatal outcome in brothers. Am J Med Genet 52(4): 406-415.
4. Cavalcanti DP, Salomao MA (1999) Dandy-Walker malformation with postaxial polydactyly: further evidence for autosomal recessive inheritance. Am J Med Genet 85(2): 183-184.
RPN Research in
Pediatrics \& Neonatology

Creative Commons Attribution 4.0 International License

\section{Research in Pediatrics \& Neonatology}

\section{Benefits of Publishing with us}

- High-level peer review and editorial services

- Freely accessible online immediately upon publication

- Authors retain the copyright to their work

- Licensing it under a Creative Commons license

- Visibility through different online platforms 